Int. J. Electrochem. Sci., 12 (2017) 3050 - 3062

\title{
An investigation of Digoxin by Cyclic Voltammetry using Gold and Silver Solid Electrodes and Chemometric Analysis
}

\author{
G. F. Bellia, H. Corrall, M. G. Baron, R. Croxton, J. Gonzalez-Rodriguez*
}

School of Chemistry, College of Science, University of Lincoln, Brayford Pool, Lincoln, LN67TS, UK. Telephone: +441522886878 .

*E-mail: jgonzalezrodriguez@lincoln.ac.uk

doi: $10.20964 / 2017.04 .60$

Received: 24 January 2017 / Accepted: 28 February 2017 / Published: 12 March 2017

Digoxin, one of the main cardiac glycosides medication, has shown to have a strong analytical response under investigation by voltammetric analysis using mercury electrodes, achieving nanomole sensitivity. In this study we investigated the suitability of solid electrodes as gold and silver electrodes in voltammetric analysis of this active pharmaceutical ingredient. The scope of the investigation was to evaluate if the use of these solid electrodes, more practical and especially less dangerous, under an operative and environmental aspects could represent a valid further possibility to add to the use of the mercury ones. Both of the solid electrodes have been tested at different $\mathrm{pH}$ of 5, 7.4, 10, and 11. PCA analysis has been performed and specific responses achieved. Micromole sensitivity has been achieved for both of the electrodes, showing that the use of these sensors could represent a preliminary analytical approach when the more accurate alternative choice is not necessary, being more practical and less environmental impacting than using mercury.

Keywords: digoxin, voltammetry, solid electrodes, PCA analysis

\section{$\underline{\text { FULL TEXT }}$}

(C) 2017 The Authors. Published by ESG (www.electrochemsci.org). This article is an open access article distributed under the terms and conditions of the Creative Commons Attribution license (http://creativecommons.org/licenses/by/4.0/). 